Pomáhajúce profesie, roč. 4, č. 2, 2021, 31-39

\title{
RELATIONSHIPS BETWEEN DEPRESSION, ANXIETY AND HEALTH-RELATED QUALITY OF LIFE IN PATIENTS WITH CARDIOVASCULAR DISEASES. THE MODERATING ROLE OF ILLNESS PERCEPTION
}

\author{
Katarína Dančová ${ }^{1}$, Tomáš Sollár ${ }^{2}$, Martina Romanová ${ }^{1}$ \\ ${ }^{1}$ Institute of Applied Psychology, Faculty of Social Sciences and Health Care, \\ Constantine the Philosopher University in Nitra, Nitra, Slovakia \\ 2Department of Psychological Sciences, Faculty of Social Sciences and Health \\ Care, Constantine the Philosopher University in Nitra, Nitra, Slovakia
}

\begin{abstract}
The present study aimed to examine the moderating role of illness perception in two relationships: a) between depression and health-related quality of life; and (b) between anxiety and health-related quality of life. A total of 108 patients with myocardial infarction and ischemic heart disease participated in the study. The patients completed the B-IPQ, HADS and HeartQoL. Illness perception moderated the relationship between depression and quality of life, and between anxiety and quality of life. The findings indicate that patients who have a more positive view of their illness have higher quality of life, despite depression and anxiety they suffer from. Positive illness perception may improve health status of patients. It has implications for interventions to maximise psychological well-being and quality of life in this patient group.
\end{abstract}

Keywords: Illness Perception; Cardiovascular Disease; Health-Related Quality of Life; Depression; Anxiety; Moderation Analysis

\section{INTRODUCTION}

The manifestation and clinical development of cardiovascular diseases is determined by factors such as excessive stress, anger, negative experiencing, depression and anxiety which are present among the cardiac patients almost three times more frequently than in a healthy population (Ruo, Rumsfeld, Hlatky, Liu, Browner \& Whooley, 2003; Bunker et al., 2003). The presence of depression and anxiety can aggravate the progression of the disease, reduce the likelihood of improvement of treatment outcomes, aggravate the ability to perceive the disease more positively, promote its recurrence and reduce quality of life (Kuper, Marmot \& Hemingway, 2002; Goldston \& Baillie, 2008; Saboya, Zimmermann \& Bodanese, 2010). In 1987, Okun and Stock emphasized the importance of subjective perceptions of quality of life rather than objective indicators of quality of life.

On the one hand anxiety and depression increase the probability of cardiovascular diseases, but on the other hand they negatively affect the course of a particular disease and general health of patients, which subsequently decreases patients' quality of life (Breznoščáková \& Kamenická, 2013). Illness perception is a factor that mediates the relationships between disease symptoms and patient's functional status expressed by experienced psychological distress or low quality of life (Tribbick et al., 2017). Hagger and Orbell (2003) assume that the way patients perceive their illness greatly influences their quality of life and psychological distress. O’Donovan, Painter, Lowe, 
Robinson \& Broadbent (2016) found out that illness perception - mainly its consequences, coherence, treatability, duration and impact on the emotional status of the patient - affects the quality of life two years after diagnosis of the illness. Illness perception influences behaviour, perceived severity of the illness, coping strategies, progression and disease outcome (Petrie, Jago \& Devcich, 2007). Kunschitz, Friedrich, Schöppl, Maitz \& Sipötz (2016) state that if cardiac patients develop negative beliefs about their illness, their treatment outcomes, quality of life and attitudes towards the treatment of cardiovascular disease are aggravated.

In the study by Petrie, Cameron, Ellis, Buick \& Weinman (2002), the hospital intervention resulted in positive changes in patients' views of their cardiovascular diseases. The patients also reported they were better prepared for leaving the hospital, subsequently could return to work and showed better subjective quality of life after only six months. Personality characteristics are expected to represent more stable traits than illness perception, which makes them less suitable for interventions aiming at improving quality of life. Broadbent, Petrie, Ellis, Ying \& Gamble (2004) found out that positive illness perception is a more important determinant of subjective well-being than objective indicators of health. Depression, anxiety and illness perception are strongly related to subjective quality of life in cardiac patients, but little is known about the impact of illness perception and personality characteristics on quality of life in cardiac patients. Especially the illness perception as a moderator in relationship between personality characteristics and quality of life should be thoroughly examined.

We intend to explore the extent to which the relationship between depression (a), anxiety (b) and quality of life is moderated by illness perception.

\section{METHODS}

\section{Participants and procedure}

The patients' participation in the study was anonymous and voluntary after signing an informed consent. Data were collected from December 2017 to March 2018 in the waiting areas of three healthcare facilities in Slovakia. The patients filled in the questionnaires individually. The inclusion criteria were age ranging from 18 to 80 years, the diagnosis of ischemic heart disease or myocardial infarction, an informed consent, and willingness to participate. The study was approved by the local ethics committees of the three healthcare facilities in Slovakia.

\section{Measures}

Personality characteristics depression and anxiety were examined by the HADS (Hospital Anxiety and Depression Scale; Zigmond \& Snaith 1983). The HADS serves as a screening tool for anxiety and depression symptoms. The self-reported questionnaire comprises 14 items; seven of them determine anxiety and the other depression. The patients rate the items on the four-point Likerttype scale and mark the answer that best reflects the way they have been feeling in the past week. Quality of life was measured by the Heart Quality of Life questionnaire which measures the degree of difficulties related to heart disease in the last four weeks of the patient's life. It consists of 14 items that are rated on the four-point Likert-type scale ranging from 0 (low quality of life) to 3 (high quality of life). There are ten items for physical score (e.g.: "Walk indoors on ground level; Garden, vacuum, carry groceries; Walk more than 100 yards at a brisk pace") and four items for emotional score (e.g.: "Not feeling relaxed and free of tension; Being depressed; Being frustrated; Being worried"). By adding the emotional and physical scores together, the global score of quality of life is obtained.

Illness perceptions were examined by the B-IPQ (Brief Illness Perception Questionnaire; Broadbent, Petrie, Main \& Weinman, 2006). The self-report questionnaire finds out beliefs about 
nine health-related dimensions, including: consequences, timeline, personal control, curability, identity, concerns, coherence, emotional response, and causes of illness. The ten-point Likert-type scale is used. A score ranges from 8 to 80 , and the higher scores indicate more threatening and negative illness perceptions. The questionnaire has adequate psychometric properties, including concurrent, predictive and discriminant validity (Broadbent et al., 2015).

\section{Statistical analysis}

The moderating effects of illness perception on the relationships between depression, anxiety and health-related quality of life were evaluated using the PROCESS macro for SPSS. Moderation analysis attempts to explain the conditions under which independent variable influences dependent variable (Hayes, 2013). We used SPSS 24.0 to perform separate hierarchical multiple regression analyses to computation power of relationships of depression and anxiety as focal predictors, illness perception as moderator variable and health-related quality of life as outcome variable.

The moderating influence of illness perception on health-related quality of life was tested using 5,000 bootstrap resamples in separate analysis. To evaluate significant interactions between independent and dependent variables, simple slopes procedure was carried out. They were evaluated at one standard deviation below, above and at the mean of the moderator variable. The Johnson-Neyman procedure was used to further identify trends in the statistical significance across all the levels of moderator values. When applying moderation analysis, we considered various criteria. We used tolerance factor and Variance Inflation Factor (VIF) to examine multicollinearity (i.e. moderation interaction correlates with the independent and moderator variable). Hayes (2013) recommends performing mean centring of independent variable and moderator variable, as we did. Scatterplots and examination of Cook's distance (Field, 2009) for each included effect size were used to identify outliers.

\section{RESULTS}

\section{Preliminary analyses}

Of the total of 129 patients approached, 110 (85.2\%) provided the informed consent. Based on the analysis of Cook's distance, two patients were excluded from analyses as outliers. The total number of cardiac patients was 108 (84\%). Mean age of 108 patients was 64.6 years (SD = 6.8); 56 (51.8 $\%$ ) were men. Coronary artery disease was in $56 \%$ of the patients and myocardial infarction was in $44 \%$ of the patients.

Table 1 Correlations of Illness Perception, Depression, Anxiety and Health-Related Quality of Life $(\mathrm{n}=108)$

\begin{tabular}{lcccc}
\hline Variables & $\boldsymbol{M} \pm \boldsymbol{S D}$ & $\mathbf{1}$ & $\mathbf{2}$ & $\mathbf{3}$ \\
\hline $\mathbf{1}$ Illness Perception & $44.31 \pm 10.63$ & - & - & - \\
$\mathbf{2}$ Depression & $6.18 \pm 3.06$ & $.397^{* *}$ & - & - \\
3 Anxiety & $8.15 \pm 3.72$ & $.429^{* *}$ & $.588^{* *}$ & - \\
$\mathbf{4}$ HRQoL global & $1.45 \pm 0.75$ & $-.593^{* *}$ & $-.387^{* *}$ & $-.529^{* *}$ \\
\hline
\end{tabular}

Notes: M-mean; SD- standard deviation; ${ }^{* *} \mathrm{p}<0.01$

The average depression and anxiety scores on the HADS were $6.18(\mathrm{SD}=3.06)$ and $8.15(\mathrm{SD}=3.72)$, respectively. Bivariate correlation analysis among variables (Table 1) showed that illness perception ( $\mathrm{r}=-0.593, \mathrm{p}=<0.01)$, depression $(\mathrm{r}=-0.387, \mathrm{p}=<0.01)$ and anxiety $(\mathrm{r}=-0.529, \mathrm{p}=<$ 
0.01 ) were negatively correlated with global health-related quality of life score. Depression ( $\mathrm{r}=$ $0.397, \mathrm{p}=<0.01)$ and anxiety $(\mathrm{r}=0.429, \mathrm{p}=<0.01)$ were positively correlated with illness perception. It means that patients with depression and anxiety symptoms perceive their illness more negatively.

\section{Moderation analyses}

\section{Relationship between depression and health-related quality of life influenced by illness perception}

Table 2 Moderation Effects of Illness Perception on Depression and Health-Related Quality of Life $(\mathrm{n}=108)$

\begin{tabular}{|c|c|c|c|c|c|c|c|}
\hline Predictor & $B$ & $S E$ & $\beta$ & $t$ & $p$ & $R^{2}$ & $\Delta R^{2}$ \\
\hline \multirow{3}{*}{$\begin{array}{l}\text { Depression } \\
\text { Illness perception } \\
\text { Depression x Illness } \\
\text { perception }\end{array}$} & -.09 & 0.02 & -.38 & $\begin{array}{c}- \\
4.32\end{array}$ & $<.001$ & .15 & \\
\hline & -.04 & 0.00 & -.59 & $\begin{array}{c}- \\
7.58\end{array}$ & $<.001$ & .35 & \\
\hline & .01 & 0.01 & .21 & 3.33 & .001 & .42 & .04 \\
\hline
\end{tabular}

Notes: B - non-standardised regression coefficient, SE - standard error of non-standardised regression coefficient, $\beta$ - standardised regression coefficient, $t$ - $t$-test, $p$ - $p$-value, $R^{2}$ - coefficient of determination, $\Delta \mathrm{R}^{2}$ - squared coefficient of determination

The results show that the relationship between depression and health-related quality of life is influenced by illness perception. Depression accounted for a significant amount of quality of life in cardiac patients, $\mathrm{R} 2=0.15, \mathrm{~F}=18.66, \mathrm{df}=106, \mathrm{p}<0.001$. It indicates that greater depression symptoms reduce the quality of life of patients. Illness perception was negatively associated with quality of life, $\mathrm{R} 2=0.35, \mathrm{~F}=57.48, \mathrm{df}=106, \mathrm{p}<0.001$. It indicates that negative illness perception reduces the quality of life of patients. The results show that illness perception affects the quality of life of patients to a greater extent than depression.

Moderation analysis revealed a significant interaction term of depression and illness perception that explained additional $4 \%$ of the variance in health-related quality of life of cardiac patients (Table 2). Both, depression and illness perception explained $42 \%$ of the variance in quality of life $(\mathrm{F}(3.104)=25.68, \mathrm{p}<0.001)$. Simple slopes analysis (Figure 1) shows that depression was significantly negatively associated with quality of life at one standard deviation below $(B=-0.09, p$ $<0.001)$ and at the mean level of illness perception $(B=-0.03, p<0.05)$, but the relationship was not significant at one standard deviation above $(B=0.01, p>0.05)$. Illness perception significantly moderated, i.e. weakened the negative relationship between depression and health-related quality of life.

Figure 1 Relationship between Depression and Health-Related Quality of Life Based on the Degree of Illness Perception. Simple slopes analysis. 
Relationship between anxiety and health-related quality of life influenced by illness perception Table 3 Moderation Effects of Illness Perception on Anxiety and Health-Related Quality of Life $(n=108)$

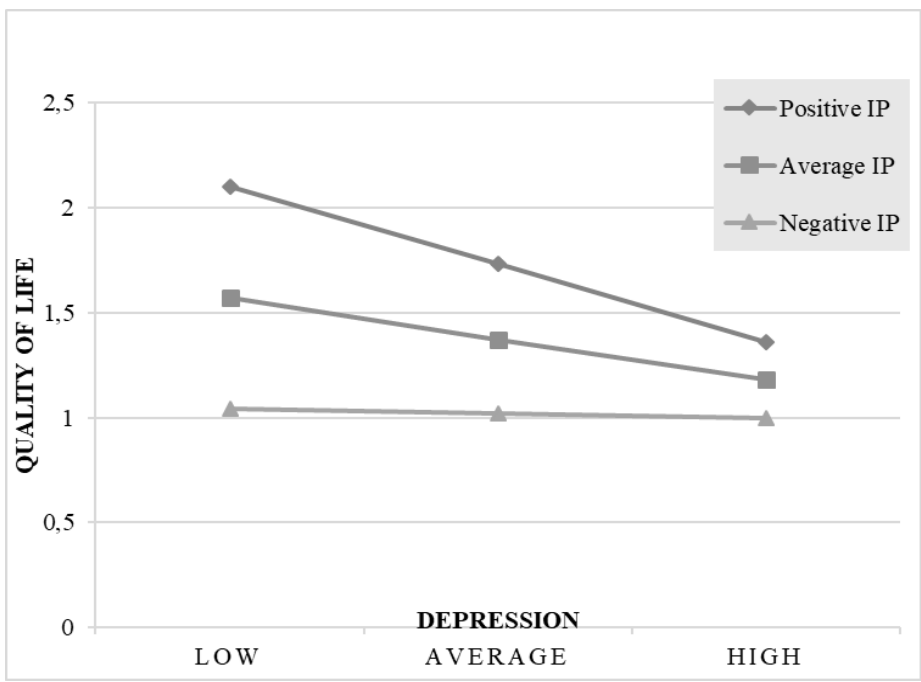

\begin{tabular}{|c|c|c|c|c|c|c|c|}
\hline Predictor & $B$ & $S E$ & $\boldsymbol{\beta}$ & $t$ & $p$ & $R^{2}$ & $\Delta R^{2}$ \\
\hline Anxiety & -.10 & 0.01 & -.52 & $6 . \overline{-}$ & $\begin{array}{c}< \\
.001\end{array}$ & .28 & \\
\hline Illness perception & -.04 & 0.00 & -.59 & $\overline{-}$ & $\begin{array}{c}< \\
.001\end{array}$ & .35 & \\
\hline $\begin{array}{l}\text { Anxiety } x \text { Illness } \\
\text { perception }\end{array}$ & .01 & 0.01 & .23 & 3.87 & .001 & .49 & .05 \\
\hline
\end{tabular}

Notes: B - non-standardised regression coefficient, SE - standard error of non-standardised regression coefficient, $\beta$ - standardised regression coefficient, $t$ - $t$-test, $p$ - $p$-value, $R^{2}$ - coefficient of determination, $\Delta \mathrm{R}^{2}$ - squared coefficient of determination

Anxiety accounted for a significant amount of quality of life in cardiac patients, $R 2=0.28, F=41.12$, $\mathrm{df}=106, \mathrm{p}<0.001$. It indicates that greater anxiety symptoms reduce the quality of life of patients. Moderation analysis revealed a significant interaction term of anxiety and illness perception that explained additional $5 \%$ of the variance in health-related quality of life of cardiac patients (Table 3 ). Both, anxiety and illness perception explained $49 \%$ of the variance in quality of life (F (3.104) $=34.10, \mathrm{p}<0.001$ ). Simple slopes analysis (Figure 2) shows that anxiety was significantly negatively associated with quality of life at one standard deviation below $(B=-0.10, p<0.001)$ and at the mean level of illness perception $(B=-0.05, p<0.05)$, but the relationship was not significant at one standard deviation above $(B=0.00, p>0.05)$. Illness perception significantly moderated, i.e. weakened the negative relationship between anxiety and health-related quality of life.

Figure 2 Relationship between Anxiety and Health-Related Quality of Life Based on the Degree of Illness Perception. Simple slopes analysis. 


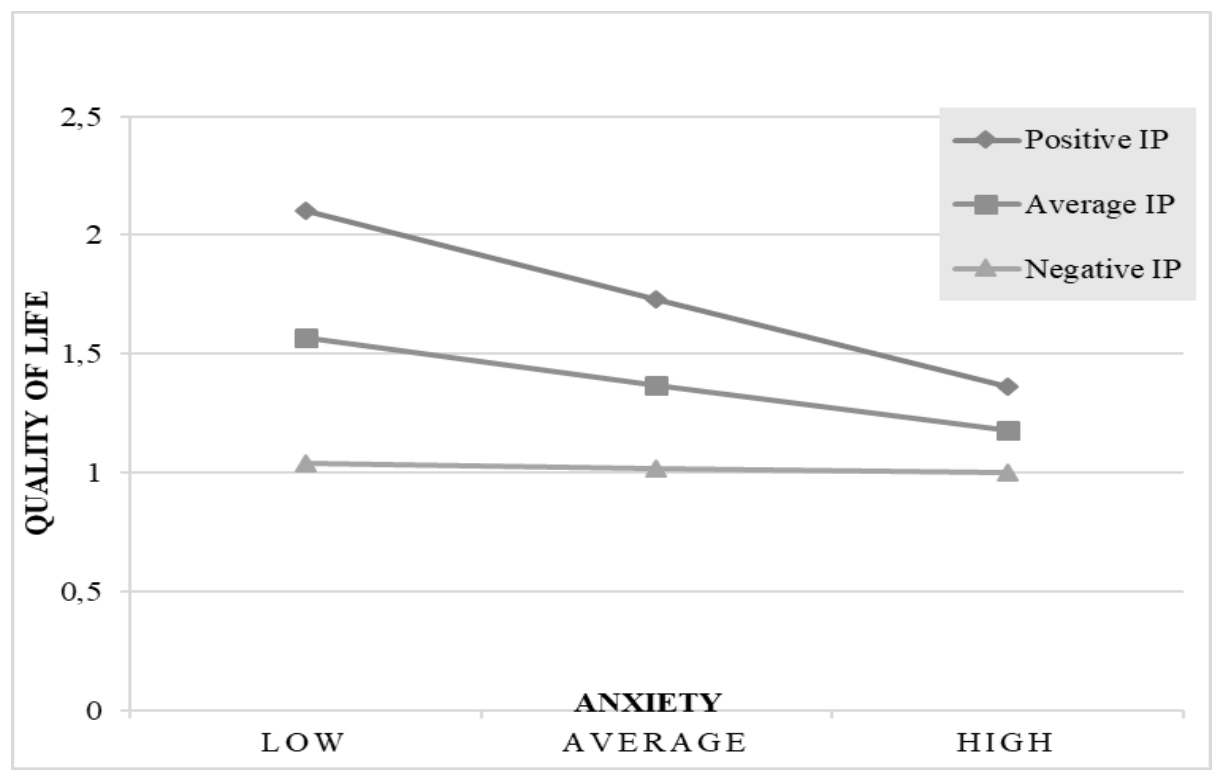

\section{DISCUSSION}

The primary aim of the study was evaluate moderating role of illness perception in two crucial relationships: (a) between depression and health-related quality of life; and (b) between anxiety and health-related quality of life.

The results suggest that the relationships are significantly moderated by illness perception. In both relationships, no association was found at high levels of illness perception. However, at moderate and low levels of illness perception, a significant relationship between depression, anxiety and quality of life was observed. The low level of illness perception means that patients have positive view of their illness. The patients do not perceive the illness as threatening or negative, and they are able to cope better with the illness and adapt easier to the conditions of health treatment. The recent studies (Knowles, Cook \& Tribbick, 2013; Knowles, Gass \& Macrae, 2013) suggest that patients with negative illness perception report increased depression and anxiety and reduced quality of life. However, our findings indicate that patients who have a more positive view of their illness have higher quality of life, despite depression and anxiety they suffer from. Patients may not have negative illness perception even if they suffer from depression or anxiety. Illness perception has a power to improve health status and to increase quality of life. Petrie et al. (2002) and Broadbent et al. (2009) suggest that we can regulate and manage our health behaviours towards better treatment outcomes through illness perception. Interventions designed to change negative illness perceptions of patients contribute to better treatment outcomes, a more positive response to illness, improved health-related quality of life, and overall improved health status of patients (Petrie et al., 2002). Also, Hallas, Wray, Andreou \& Banner (2011) found out that depression and negative illness perception lead to maladaptive coping strategies in patients with heart failure.

Many studies on illness perception are based on the specific theoretical model - the SRM (the selfregulation model of health and illness; Leventhal, Diefenbach \& Leventhal, 1992). According to the model, patients create cognitive and emotional representations that help them understand their illness and provide the basis for coping with their illness. The model consists of eight major dimensions of illness perception. They are beliefs about the consequences of illness, timeline of 
illness (cyclical or permanent), control (personal or treatment), identity, concerns, coherence and emotional response. In the present study, however, we examined illness perception from the holistic perspective and not from the perspective of individual dimensions. The findings by Morgan, Villiers-Tuthill, Barker \& McGee (2014) suggest that the importance of the individual dimensions should not be emphasised; the focus should be primarily on the overall dynamism of the patient's illness representation, i.e. the system of beliefs about the illness. At a practical level, the findings indicate that illness perception may potentially be included in the list of psychological risk factors related to depression and anxiety in patients with heart failure (Morgan et al., 2014).

Many patients report health problems despite objectively positive prognoses. It is important to identify beliefs the patients develop about their illness. Based on the study results, we found out that quality of life is affected more by illness perception than by patients' personality characteristics. Broadbent et al. (2004) state that positive illness perception is a more important determinant of subjective well-being than objective health indicators. The treatment of patients with cardiovascular diseases should not only be characterised by unilateral treatment of the illness but also by the alleviation of depression and anxiety symptoms while focusing more on illness perception. Although most cardiovascular diseases cannot be cured, the picture that patients create about their illness is very important because it defines their behaviour and affects the course of the illness and their quality of life.

\section{Limitations and Strengths}

There is lack of evidence about the impact of illness perception and personality characteristics on quality of life in cardiac patients so further research is needed. The limitations in our study could be small sample size, self- report measurement tools, Slovak- speaking patients only. Another limitation could be that the questionnaire examined the quality of life; comorbidity naturally increases with older age; for the patients it was difficult to answer questions with focus on the heart disease and to ignore other accompanying phenomena caused by other illnesses. The fact that data were collected individually is also considered as one of the strengths of the study. Direct contact with each patient enabled us to evaluate the plausibility of answers and eliminate the presence of missing or unintelligible answers.

\section{CONCLUSIONS}

We found out that patients who have a more positive view of their illness have higher quality of life, despite depression and anxiety they suffer from. The patients do not perceive the illness as threatening or negative, and they are able to cope better with their illness and adapt to the conditions of health treatment. As stated by Morgan et al. (2014), the concept of illness perception may potentially be included in the list of psychological risk factors related to depression and anxiety in patients with heart failure. Therefore, if patients perceive their illness more positively, they may not experience symptoms of depression and anxiety that cause difficulties in coping with the illness. The results of the present study may serve as an information framework that emphasises the importance of working with positive illness perception. However, further investigation is necessary to confirm the mechanism of action of illness perception as a determinant of quality of life in patients with cardiovascular diseases.

\section{FUNDING DETAILS}

This study was supported by the research project UGA IX/1/2020 Quality of life and coping after stroke and project VEGA 1/0418/19 Coping strategies in recovery after stroke. 


\section{DECLARATION OF INTEREST STATEMENT}

None.

\section{REFERENCES}

Bunker, S. J., Colquhoun, D. M., Esler, M. D., Hickie, I. B., Hunt, D., Jelinek, V. M., ... \& Tonkin, A. M. (2003). "Stress" and coronary heart disease: psychosocial risk factors. Medical Journal of Australia, 178(6), 272-276. doi: https://doi.org/10.5694/j.1326-5377.2003.tb05193.x

Breznoščáková, M. D., \& Kamenická, L. (2013). Výskyt depresívnych a úzkostných symptómov u pacientov s kardiovaskulárnym ochorením. Psychiatria pre prax,14(4), 164-167. Retrieved: http://www.solen.sk/pdf/f02677ee31e65ae0ee4af4bd29b8f69a.pdf

Broadbent, E., Ellis, C. J., Thomas, J., Gamble, G., \& Petrie, K. J. (2009). Further development of an illness perception intervention for myocardial infarction patients: a randomized controlled trial. Journal of psychosomatic research, 67(1), 17-23. doi: 10.1016/j.jpsychores.2008.12.001

Broadbent, E., Petrie, K., Ellis, C., Ying, J., \& Gamble, G. (2004). A picture of health--myocardial infarction patients' drawings of their hearts and subsequent disability: a longitudinal study. Journal of Psychosomatic Research, 57(6), 583-587. doi: 10.1016/j.jpsychores.2004.03.014

Broadbent, E., Petrie, K. J., Main, J., \& Weinman, J. (2006). The brief illness perception questionnaire. Journal of psychosomatic research,60(6), 631-637. doi: 10.1016/j.jpsychores.2005.10.020

Broadbent, E., Wilkes, C., Koschwanez, H., Weinman, J., Norton, S., \& Petrie, K. J. (2015). A systematic review and meta-analysis of the Brief Illness Perception Questionnaire. Psychology \& Health, 30(11), 1361-1385. doi: 10.1080/08870446.2015.1070851

Field, A. (2009). Discovering statistics using SPSS (3nd ed.). London: SAGE Publications

Goldston, K., \& Baillie, A. J. (2008). Depression and coronary heart disease: a review of the epidemiological evidence, explanatory mechanisms and management approaches. Clinical psychology review, 28(2), 288-306. doi: https://doi.org/10.1016/j.cpr.2007.05.005

Hagger, M. S., \& Orbell, S. (2003). A meta-analytic review of the common-sense model of illness representations. Psychology and health, 18(2), 141-184. doi: 10.1080/088704403100081321

Hallas, C.N., Wray, J., Andreou, P., \& Banner, N.R. (2011). Depression and perceptions about heart failure predict quality of life in patients with advanced heart failure. Heart \& Lung: The Journal of Acute and Critical Care, 40(2), 111-121. http://dx.doi.org/10.1016/j.hrtlng.2009.12.008.

Hayes, A. F. (2013). Introduction to Mediation, Moderation, and Conditional Process Analysis: A Regression-Based Approach. NewYork: The Guilford Press.

Knowles, S. R., Cook, S. I., \& Tribbick, D. (2013). Relationship between health status, illness perceptions, coping strategies and psychological morbidity: A preliminary study with IBD stoma patients. Journal of Crohn's and Colitis, 7(10), e471 - e478. doi: 10.1016/j.crohns.2013.02.022

Knowles, S. R., Gass ,C., \& Macrae, F. (2013). Illness perceptions in IBD influence psychological status, sexual health and satisfaction, body image and relational functioning: A preliminary 
exploration using Structural Equation Modeling. Journal of Crohn's and Colitis, 7(9), 344 - 350. doi: 10.1016/j.crohns.2013.01.018

Kunschitz, E., Friedrich, O., Schöppl, Ch., Maitz, J., \& Sipötz, J. (2016). Illness perception patterns in patients with Coronary Artery Disease. Psychology, Health \& Medicine, 22(8), 940-946. doi: 10.1080/13548506.2016.1271439

Kuper, H., Marmot, M., \& Hemingway, H. (2002). Systematic review of prospective cohort studies of psychosocial factors in the etiology and prognosis of coronary heart disease. In Seminars in vascular medicine, 2(3), 267-314. doi: 10.1055/s-2002-35401

Leventhal, H, Diefenbach, M, \& Leventhal, E. (1992). Illness cognition: Using common sense to understand treatment adherence and affect cognition interactions. Cognitive Therapy and Research, 16(2), 143-163. doi: 10.1007/BF01173486.

Morgan, K., Villiers-Tuthill, A., Barker, M., \& McGee, H. (2014). The contribution of illness perception to psychological distress in heart failure patients. BMC psychology, 2(1), 50. doi: 10.1186/s40359-014-0050-3

O’Donovan, C. E., Painter, L., Lowe, B., Robinson, H., \& Broadbent, E. (2016). The impact of illness perceptions and disease severity on quality of life in congenital heart disease. Cardiology in the young, 26(1), 100-109. doi: 10.1017/S1047951114002728

Okun, M. A., \& Stock, W. A. (1987). The construct validity of subjective well-being measures: An assessment via quantitative research syntheses. Journal of Community Psychology, 15(4), 481-492. doi: https://doi.org/10.1002/1520-6629(198710)15:4<481::AID-JCOP2290150406>3.0.CO;2-E

Petrie, K., Jago, L., \& Devcich, D. (2007). The role of illness perceptions in patients with medical conditions. Current Opinion Psychiatry, 20(2), 163. doi: 10.1097/YC0.0b013e328014a871

Petrie, K., Cameron, L., Ellis, C., Buick, D., \& Weinman, J. (2002). Changing Illness Perceptions After Myocardial Infarction: An Early Intervention Randomized Controlled Trial. Psychosomatic medicine, 64(4), 580-586. doi: 10.1097/00006842-200207000-00007

Ruo, B., Rumsfeld, J. S., Hlatky, M. A., Liu, H., Browner, W. S., \& Whooley, M. A. (2003). Depressive symptoms and health-related quality of life: The Heart and Soul Study. Journal of the American Medical Association, 290(2), 215-221. doi: 10.1001/jama.290.2.215

Saboya, P. M., Zimmermann, P. R., \& Bodanese, L. C. (2010). Association between anxiety or depressive symptoms and arterial hypertension, and their impact on the quality of life. The International Journal of Psychiatry in Medicine,40(3), 307-320. doi: https://doi.org/10.2190/PM.40.3.f

Tribbick, D., Salzberg, M., Connell, W., Macrae, F., Kamm, M., Bates, G., ... \& Knowles, S. (2017). Differences across illness perceptions in inflammatory bowel disease and their relationships to psychological distress and quality of life.Gastroenterology Nursing, 40(4), 291-299. doi: 10.1097/SGA.0000000000000225

Zigmond, A. S., \& Snaith, R. P. (1983). The hospital anxiety and depression scale. Acta psychiatrica scandinavica, 67(6), 361-370. 